\title{
Restriction of Germline Proliferation by Soft X-ray Irradiation of Chicken Embryos and its Application to Chimera Production
}

\author{
Yusuke Atsumi ${ }^{1,2}$, Takahiro Tagami ${ }^{3}$, Hiroshi Kagami ${ }^{1}$ and Tamao Ono ${ }^{1}$ \\ ${ }^{1}$ Faculty of Agriculture, Shinshu University, 8304 Minamiminowa, Kamiina, Nagano 399-4598, Japan \\ ${ }^{2}$ Interdisciplinary Graduate School of Science and Technology, Shinshu University, \\ 8304 Minamiminowa, Kamiina, Nagano 399-4598, Japan \\ ${ }^{3}$ National Institute of Livestock and Grassland Science, Tsukuba, Ibaraki 305-0901, Japan
}

\begin{abstract}
Primordial germ cells (PGCs) are the progenitor cells of gametes. Avian PGCs are located in the central region of the area pellucida at the blastoderm stage. PGCs enter the circulation soon after the formation of blood vessels in incubating eggs and eventually settle in the gonadal primordium. We have now examined exposure of chicken embryos to soft (low-energy) $\mathrm{x}$-rays as a means of depleting endogenous PGCs and thereby improving the efficiency of chimera production. The blastoderm of White Leghorn eggs was exposed to soft x-rays for 0, 20, 40 or $60 \mathrm{~s}$ before incubation. The irradiated embryos manifested delayed development at $60 \mathrm{~h}$ of incubation. They also showed reduced numbers of circulating PGCs at stages 14 and 15 and of gonadal PGCs at stage 30. The hatchability of irradiated embryos was lower than that of nonirradiated controls. Irradiation for $20 \mathrm{~s}$ was found to provide the best outcome taking into consideration both the restriction of PGC proliferation and hatchability. Dispersed blastoderm cells of quail (black plumage) embryos were introduced into the blastoderm of chicken embryos irradiated for $20 \mathrm{~s}$ or of nonirradiated embryos. The number of donor-derived PGCs was higher in the irradiated embryos than in the nonirradiated controls at stage 30. These results suggest that soft $\mathrm{x}$-irradiation of chicken embryos is a feasible approach to depletion of endogenous germ cells and consequent improvement in the efficiency of incorporation of donor PGCs.
\end{abstract}

Key words: blastoderm, chimera, embryo culture, primordial germ cells, soft x-ray

\section{Introduction}

Primordial germ cells (PGCs) are the first identifiable progenitors of gametes and provide the only cellular continuity between generations. Avian PGCs are located in the central region of the area pellucida at the blastoderm stage, and they migrate to the extraembryonic germinal crescent shortly after the onset of incubation. As soon as blood vessels form, the PGCs enter the circulation and finally settle in the gonadal primordium (Gilbert, 2006). Attempts have been made to produce avian germline chimeras and donor-derived offspring by the transfer of blastoderm cells or PGCs into host embryos (Petitte et al., 1990; Kagami et al., 2002; Naito, 2003a, b; Kim et al., 2005). Such procedures will likely play an important role in the preservation of foundation stocks and endangered species (Tajima et al., 1993). Development of a more effective technology for the expression of donor-derived germ cells will require improvement in the efficiency of

Received: May 7, 2008, Accepted: May 29, 2008

Correspondence: Dr. T. Ono, Faculty of Agriculture, Shinshu University, 8304 Minamiminowa, Kamiina, Nagano 399-4598, Japan.

(E-mail: tamaoon@shinshu-u.ac.jp) germline transmission. The production of germline chimeras requires incorporation of donor PGCs into the endogenous gonadal tissue of recipient embryos. The proportion of donor-derived gametes, however, is determined by the relative numbers of the donor- and recipientderived germ cells in the chimeric gonad. This proportion would be expected to be increased if the PGCs of the recipient could be removed, depleted, or inactivated. The ideal recipient, therefore, would be a healthy animal that has normal reproductive organs but which is sterile as a result of the absence only of the germ cells themselves ( $\mathrm{Li}$ et al., 2001). Exposure to soft (low-energy) x-rays has been shown to be effective in restricting the proliferation of quail and chicken PGCs (Li et al., 2001; Lim et al., 2006; Nakamichi et al., 2006). We have now examined the effect of such x-irradiation on the number of PGCs in chicken embryos, and we have evaluated the utility of this approach for the preparation of recipient chicken embryos for the production of germline chimeras.

\section{Materials and Methods}

\section{Animals}

The study was performed in accordance with the policies on animal care developed by the Animal Care and 
Management Committee of Shinshu University. Fertilized White Leghorn (Gallus domesticus) eggs were obtained from Goto Hatchery (Gifu, Japan). Japanese quail (Coturnix japonica) with black plumage were maintained in our laboratory, and fertilized eggs were collected daily. The developmental stage of embryos was determined on the basis of the normal tables of Eyal-Giladi and Kochav (1976) or Hamburger and Hamilton (1951) for stages before incubation (expressed in Roman numerals) or after incubation (expressed in Arabic numerals), respectively.

\section{Irradiation}

A fertilized chicken egg was cracked open and transferred to a dish. The surrounding thick albumen was removed, and the blastoderm on the naked egg yolk was positioned upward. The egg was then placed on a turntable in the chamber of a soft X-ray apparatus (model B-4; Softex, Tokyo, Japan). The table was rotated at $6 \mathrm{rpm}$, and the blastoderm was placed at a distance of $21 \mathrm{~cm}$ from the soft $\mathrm{x}$-ray source $(18 \mathrm{kV}, 2 \mathrm{~mA})$. Embryos were irradiated for $0,20,40$ or $60 \mathrm{~s}$ and were designated $\mathrm{X}-0, \mathrm{X}$ $20, \mathrm{X}-40$ and $\mathrm{X}-60$ accordingly. The radiation dosage was estimated as $2.0 \mathrm{~Gy} / \mathrm{min}$ on the basis of data supplied by Softex showing the dosage to be 2.96 or $0.61 \mathrm{~Gy} / \mathrm{min}$ at distances of 185 and $343 \mathrm{~mm}$, respectively, and at settings of $20 \mathrm{kV}$ and $2 \mathrm{~mA}$.

\section{Embryo Culture}

Manipulated embryos were cultured for $\sim 6.5$ days until they reached stage 30 or until hatching using a previously described method (systems II and III; Perry, 1988; Naito et al., 1990).

\section{Counting of Circulating PGCs}

Cultured embryos at stages 14 to 17 were transferred to new dishes for collection of $2 \mu l$ of blood from the dorsal aorta. The blood was diluted with $18 \mu \mathrm{l}$ of Dulbecco's modified Eagle's medium (Gibco BRL, Grand Island, NY, USA) supplemented with $10 \%$ fetal bovine serum (Nippon Bio-test Laboratories, Tokyo, Japan), and a welldispersed sample was transferred to a hemocytometer for enumeration of PGCs and erythrocytes.

\section{Population of Gonadal PGCs}

Embryos at stage 30 were removed from the yolk and fixed in Bouin's fluid. The gonadal tissue was serially sectioned at a thickness of $7 \mu \mathrm{m}$, and the sections were processed for immunohistochemical detection of gonadal PGCs with antibodies to the chicken vasa homolog (CVH) protein (Nakamura et al., 2007) as described previously (Ono et al., 1998). The population of PGCs was enumerated by counting the number of stained PGCs in 10 sections (every fourth serial section) in the middle region of the left gonad.

\section{Production of Chimera}

The area pellucida of quail blastoderm was isolated from the yolk and suspended in Dulbecco's modified Eagle's medium supplemented with $10 \%$ chicken serum (Nippon Bio-test Laboratories). A portion $(1 \mu \mathrm{l})$ of the blastoderm cell suspension (containing 3000 cells) was injected into the area pellucida of an unincubated chick embryo that had been irradiated for $20 \mathrm{~s}$ or not prior to the injection. Donor-derived PGCs in chimeric embryos at stage 30 were identified and counted by immunohistochemical analysis with the QCR1 antibody, which recognizes a protein specific to quail PGCs (Aoyama et al., 1992; Ono et al., 1998), as described above.

\section{Statistical Analysis}

Data were analyzed by Student's $t$ test, Welch's $t$ test, the Mann-Whitney's $U$ test, Scheffe's $F$ test, or Spearman's correlation coefficient by rank test with the use of the Statcel add-in program for Microsoft Excel (Yanai, 2004) or by Fisher's exact probability test (http://aoki2.si. gunma-u.ac.jp/javascript/fisherexacttest.html). A $P$ value of $<0.05$ was considered statistically significant.

\section{Results}

\section{Embryonic Development and Hatchability}

Embryos exposed to soft x-rays and cultured according to system II showed delayed development compared with control embryos (Fig. 1). After $60 \mathrm{~h}$ of incubation, the median developmental stage of normal (noncultured, nonirradiated) embryos was stage 17 whereas that of cultured (X-0) embryos was stage $16(P<0.05$ versus normal) and that of irradiated (X-20, X-40 or X-60) embryos was stage $15(P<0.05$ versus $\mathrm{X}-0)$. Hatching rates were $34 \%(28 /$ $83), 18 \%(22 / 124), 9 \%(9 / 105)$ and $3 \%(5 / 163)$ for the $\mathrm{X}-0, \mathrm{X}-20, \mathrm{X}-40$ and $\mathrm{X}-60$ embryos, respectively, compared with a hatchability of $82 \%$ (37/45) for normal embryos (Fig. 2). The hatchability of cultured (X-0) embryos was significantly lower than that of normal embryos $(P<0.05)$ and it was decreased by $\mathrm{x}$-irradiation in a dose-dependent manner $(P<0.05)$.

\section{Population of Circulating and Gonadal PGCs}

We next determined the densities of circulating PGCs and erythrocytes in embryos at stages 14 to 17 that had been exposed to soft x-rays before culture. The density of PGCs in the bloodstream of nonirradiated (normal or X$0)$ embryos was decreased in a developmental stagedependent manner $(P<0.05$, Spearman's correlation coefficient by rank test), with that for cultured (X-0) embryos not differing from that for normal embryos at each stage (Fig. 3A). At stage 14, the PGC density in X40 or X-60 embryos was significantly lower than that in X0 embryos $(P<0.05)$; at stage 15 , that in $\mathrm{X}-20, \mathrm{X}-40$ or $\mathrm{X}$ 60 embryos was significantly lower than that in $\mathrm{X}-0$ embryos $(P<0.05)$. The density of erythrocytes did not differ significantly between the nonirradiated and irradiated groups at any stage examined (Fig. 3B).

Gonadal PGCs were visualized immunohistochemically with antibodies to $\mathrm{CVH}$ at stage 30 (Fig. 4). The number of PGCs in cultured (X-0) embryos $(221 \pm 29$, mean \pm SE) was significantly reduced compared with that in normal embryos (404 $\pm 12, P<0.05)$. The number of PGCs was reduced by $\mathrm{x}$-irradiation in a dose-dependent manner $(P<0.05)$, with the values for $\mathrm{X}-20, \mathrm{X}-40$ and $\mathrm{X}$ 60 embryos being $153 \pm 19,154 \pm 44$ and $97 \pm 25$, respectively. 

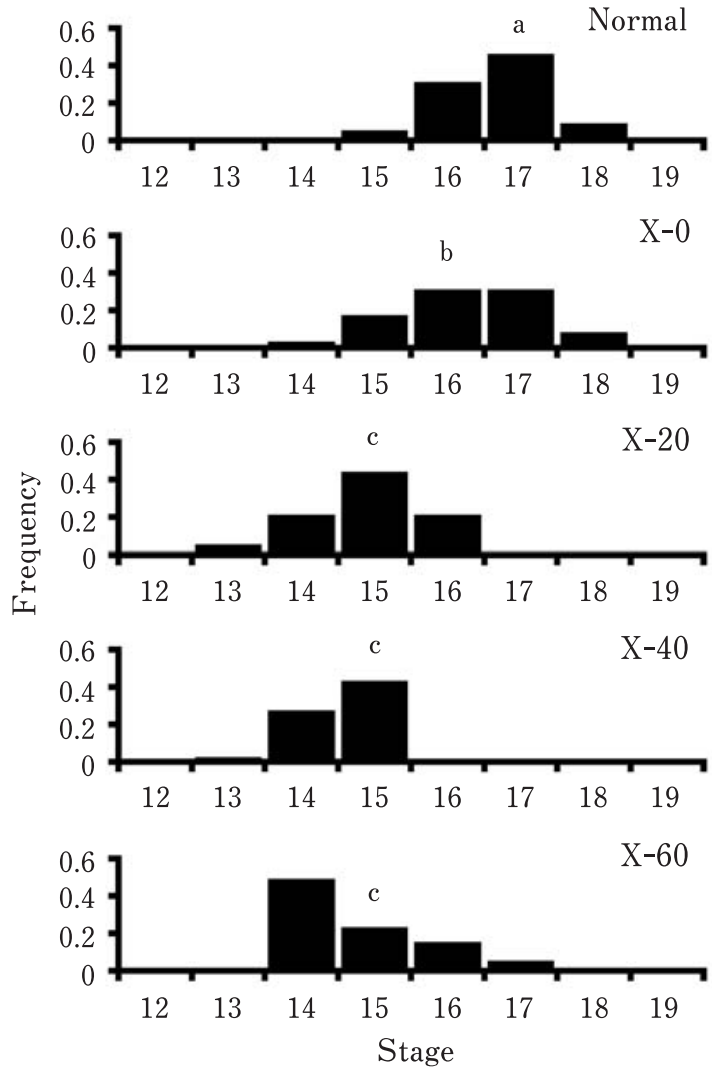

Fig. 1. Effect of soft $x$-irradiation of the distribution of developmental stages of chicken embryos at $60 \mathrm{~h}$ of culture. Embryos were exposed to soft $\mathrm{x}$-rays for $0 \mathrm{~s}$ (X-0), 20s (X-20), 40s (X-40) or 60s (X-60) before incubation. The distribution for normal embryos is shown for comparison. Each group comprised 17 to 29 embryos. Lowercase letters $(\mathrm{a}, \mathrm{b}, \mathrm{c})$ indicate the median values as well as significant differences $(P<0.05)$ between the medians of normal and $\mathrm{X}-0$ groups and between those of X-0 and irradiated (X-20, X-40 or X60) groups (Mann-Whitney's $U$ test).

\section{Chimera Production}

For chimera production, chick embryos were exposed to soft $\mathrm{x}$-rays for $0 \mathrm{~s}$ (X-0) or $20 \mathrm{~s}$ (X-20), injected with quail blastoderm cells, and incubated until stage 30 . Transferred quail PGCs were positively stained with QCR1 antibody in the chick embryonic gonads (Fig. 5A, 5B). The number of donor-derived quail PGCs in left gonadal tissue of the chick embryos was then determined immunohistochemically with the QCR1 antibody (Fig. 5C). The population of quail PGCs in X-20 embryos (26.5 \pm 3.6$)$ was greater than that in X-0 embryos $(15.2 \pm$ 2.7, $P<0.05)$. Chimera hatchlings with quail-derived black plumage were obtained from both $\mathrm{X}-0$ and $\mathrm{X}-20$ embryos (Fig. 6).

\section{Discussion}

The vasa gene is thought to be a reliable molecular

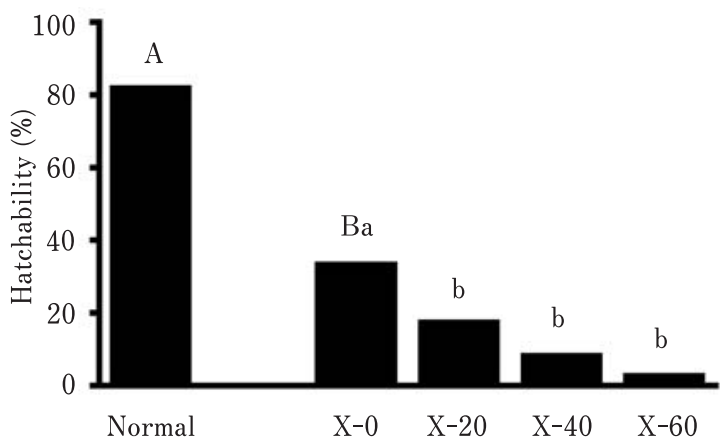

Fig. 2. Effect of soft $x$-irradiation of the hatchability of chicken embryos. Embryos were exposed to soft $\mathrm{x}$-rays for $0 \mathrm{~s}(\mathrm{X}-0, n=83), 20 \mathrm{~s}(\mathrm{X}-20, n=124), 40 \mathrm{~s}(\mathrm{X}-40, n$ $=105)$ or $60 \mathrm{~s}(\mathrm{X}-60, n=163)$ before incubation. The hatchability of normal embryos $(n=45)$ is shown for comparison. Hatchabilities of normal versus cultured (X-0) embryos and $\mathrm{X}-0$ versus irradiated (X-20, X-40 or $\mathrm{X}-60)$ embryos differed significantly as indicated by the different letters $(P<0.05$, Fisher's exact probability test). Hatchability was also decreased by soft $x-$ irradiation in a dose-dependent manner $(P<0.05$, Spearman's correlation coefficient by rank test).

marker for tracing the origin of the germline. Its homolog in the chicken, $c v h$, has been isolated and applied to trace the origin and movement of PGCs (Tsunekawa et al., 2000), resulting in the detection of $\sim 30 \mathrm{CVH}$-expressing PGCs in the central zone of the area pellucida of White Leghorn embryos at stage $\mathrm{X}$. The population of $\mathrm{CVH}$ expressing PGCs was recently shown to increase gradually from stage $X(\sim 130$ cells $)$ to stage $10(\sim 440$ cells $)$ in Rhode Island Red embryos (Nakamura et al., 2007). The difference in the size of the PGC population at stage $\mathrm{X}$ between these two previous studies may be due to the strain difference (Nakamura et al., 2007). The proliferation of avian PGCs occurs during their migratory period before they settle in the germinal ridge (Nakamichi et al., 2006). The population of chicken PGCs in the circulation around stage 14 is several hundred or more, although it varies among eggs (Tajima et al., 1999; Zhao et al., 2003).

Chicken embryos exposed to soft $\mathrm{x}$-rays in the present study manifested delayed development at $60 \mathrm{~h}$ of culture, and this developmental delay persisted until hatching. The irradiated embryos thus hatched one or more days later than the X-0 embryos (data not shown). The hatchability of embryos also decreased in a manner dependent on the dose of radiation. In addition, the hatchability of cultured (X-0) embryos was markedly reduced compared with that of intact eggs, suggesting a need for improvement in culture techniques. Culture of chick embryos from stage $\mathrm{X}$ with the use of embryo culture systems II and III was previously shown to result in a hatching rate of 50.0 to $62.5 \%$ (Naito and Perry, 1989; Naito et al., 1990).

Soft $\mathrm{x}$-irradiation of chicken embryos in the present 
A
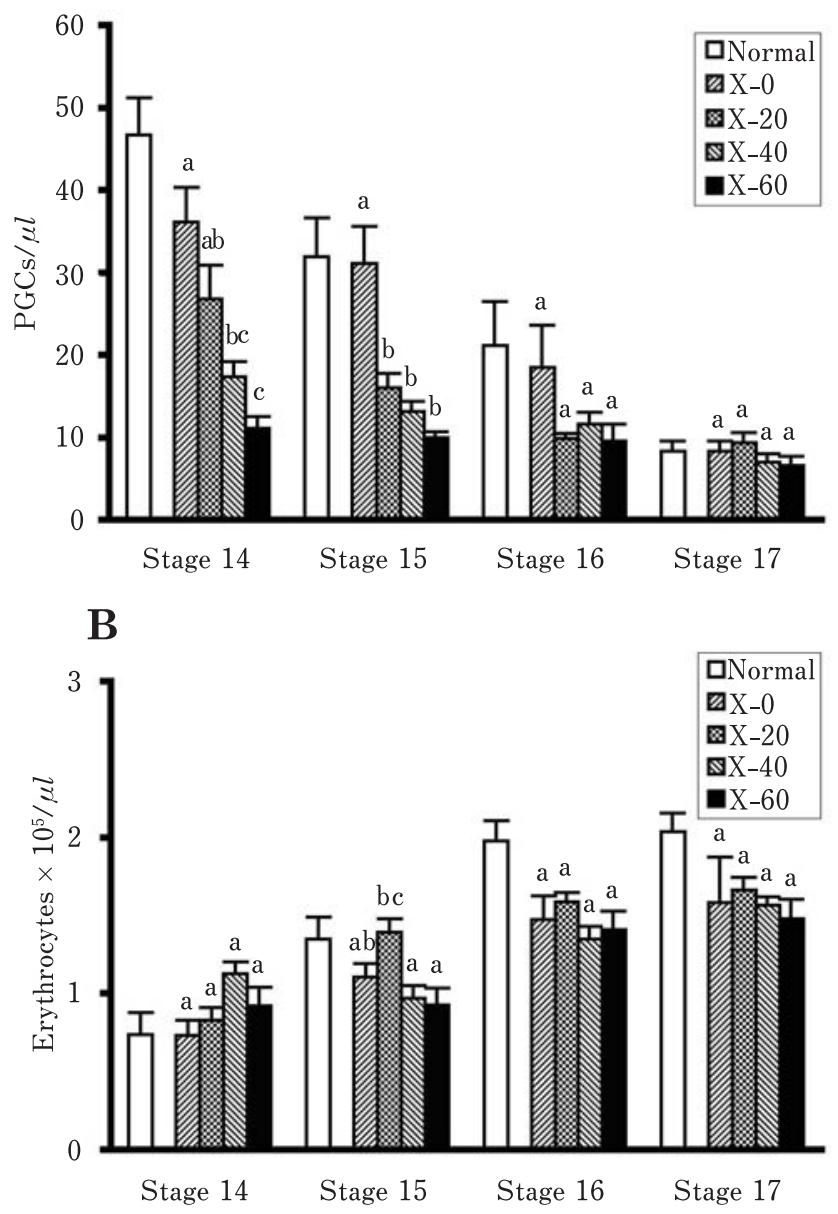

Fig. 3. Effect of soft $x$-irradiation on the density of PGCs or erythrocytes in the bloodstream of chicken embryos. Embryos were exposed to soft $\mathrm{x}$-rays for $0 \mathrm{~s}$ (X-0), 20s (X-20), 40s (X-40) or 60s (X-60) before incubation, and the density of PGCs (A) or erythrocytes (B) in the circulation was determined at stages 14 to 17 . The values for normal embryos are shown for comparison and did not differ from those for cultured (X-0) embryos at each stage (Student's $t$ test). Lowercase letters (a, b, c) indicate significant differences based on Scheffe's $F$ test $(P<0.05)$. Data are means + SE from 5 to 10 embryos.

study resulted in depletion of endogenous PGCs. The number of circulating PGCs at stage 14 or 15 in embryos irradiated at the blastoderm stage was thus markedly reduced compared with that in cultured (X-0) embryos. Exposure to soft $\mathrm{x}$-rays had previously been found to reduce the number of circulating PGCs in quail (Li et al., 2001), White Leghorn (Lim et al., 2006), and Barred Plymouth Rock (Nakamichi et al., 2006) embryos. The extent of the reduction in the number of circulating PGCs differed among these studies, likely because of differences in the apparatus for $\mathrm{x}$-irradiation and in the avian strains.

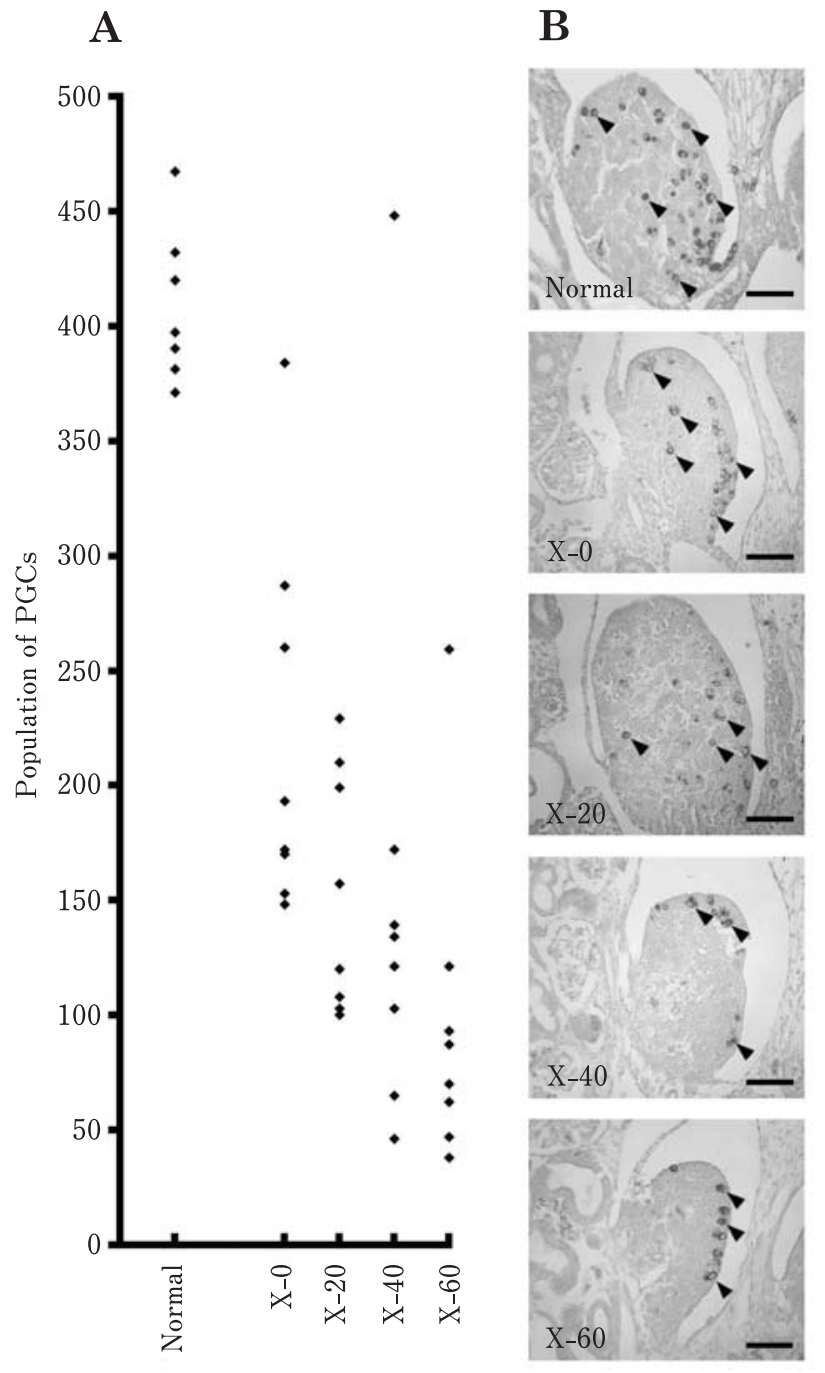

Fig. 4. Effect of soft $x$-irradiation on the population of PGCs in the left gonad of chicken embryos. (A) Embryos were exposed to soft $\mathrm{x}$-rays for $0 \mathrm{~s}$ (X-0), $20 \mathrm{~s}$ (X-20), 40s (X-40) or 60s (X-60) before incubation until stage 30, when the number of PGCs in the left gonad was determined by immunohistochemistry with antibodies to CVH. Each dot indicates the value for one embryo ( $n=8$ for all groups). Values for normal embryos are shown for comparison. The PGC population of cultured (X-0) embryos was significantly smaller than that of normal embryos $(P<0.05$, MannWhitney's $U$ test), and it was decreased by $\mathrm{x}$ irradiation in a dose-dependent manner $(P<0.05$, Spearman's correlation coefficient by rank test). (B) Representative immunohistochemistry images for embryos treated as in (A). Arrowheads indicate PGCs. Scale bars, $50 \mu \mathrm{m}$.

The population of gonadal PGCs in the present study was also reduced by soft $\mathrm{x}$-irradiation in a dose-dependent manner. X-irradiation induces DNA damage, cell cycle arrest, and apoptosis, with such treatment having been 

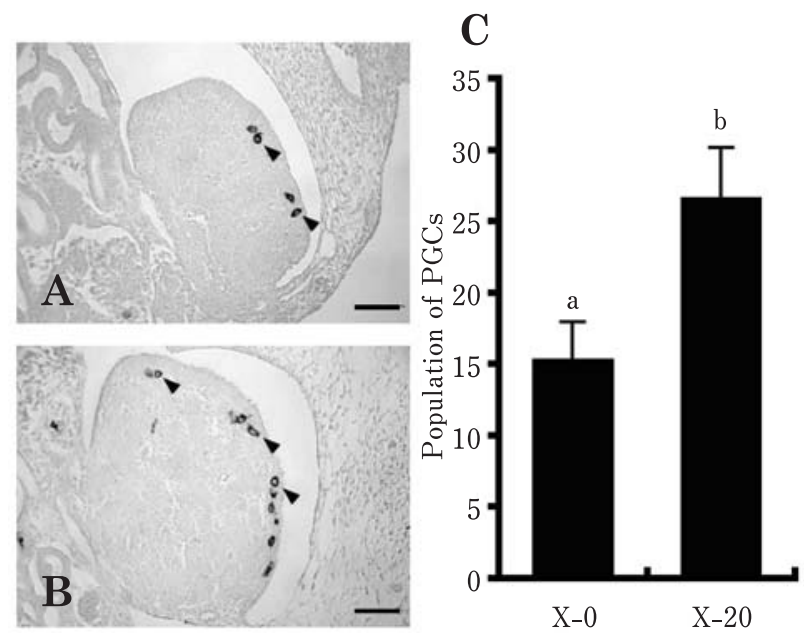

Fig. 5. Effect of soft $x$-irradiation on the population of donor-derived (quail) PGCs in the left gonad of chicken embryos. Chicken embryos were exposed to soft $\mathrm{x}$-rays for $0 \mathrm{~s}$ (X-0) or $20 \mathrm{~s}$ (X-20), injected with quail blastoderm cells, and incubated until stage 30 , when the number of donor-derived PGCs in left gonadal tissue was determined immunohistochemically with the QCR1 antibody. (A, B) Representative immunohistochemistry images for X-0 and X-20 embryos, respectively. Scale bars, $50 \mu \mathrm{m}$. (C) Population of donor-derived PGCs in left gonadal tissue. Data are means $+\mathrm{SE}$ for 13 embryos and differed significantly between $\mathrm{X}-0$ and $\mathrm{X}$-20 embryos ( $P<0.05$, Welch's $t$ test), as indicated by the lowercase letters $(a, b)$.

shown to delay or arrest mitosis in rat spermatogonia but not to affect the proliferation of somatic cells (West and Lähdetie, 2001). Our results suggest that x-irradiation inhibits the mitotic activity of PGCs, possibly by inducing apoptosis, without affecting that of somatic cells including erythrocytes and gonadal cells. Although the proliferation of blastodermal PGCs appeared to be impaired by $\mathrm{x}$ irradiation, the susceptibility of these cells to this treatment varied markedly among embryos (Fig. 4A).

Depletion of endogenous PGCs would be expected to increase the chance of incorporation of donor PGCs and therefore to increase the proportion of the donor cells in the gonads of chimeric embryos. Such depletion of endogenous PGCs, however, is associated with a reduction in hatchability. Taking into account these conflicting effects of x-irradiation, we adopted an irradiation time of $20 \mathrm{~s}$ (a radiation dose of $\sim 0.7 \mathrm{~Gy}$ ) for chimera production in the present study. The ratio of the number of endogenous gonadal PGCs in X-20 embryos to that in X-0 embryos was 0.7 at stage 30 , which resulted in a 1.7 -fold increase in the number of donor-derived PGCs in X-20 embryos relative to that in $\mathrm{X}-0$ embryos.

Donor testis cells isolated from a fertile male mouse were able to undergo spermatogenesis when transplanted into the seminiferous tubules of an infertile male mouse

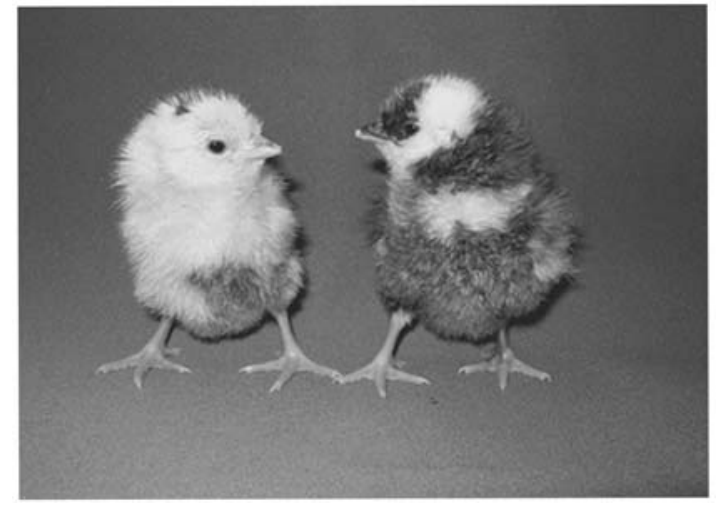

Fig. 6. Chimera hatchlings born from X-0 (left) and X20 (right) chick embryos. The black plumage is derived from the donor quail cells of chimeric chick embryos produced as in Fig. 5.

(Brinster and Avarbock, 1994; Brinster and Zimmermann, 1994; Ogawa et al., 1997). Similarly transplanted rat testis cells also underwent spermatogenesis in the testis of immunodeficient mice (Clouthier et al., 1996; Shinohara et al., 2006). In the present study, donorderived quail PGCs had settled in the gonads of chicken embryos at stage 30 . It was also shown that the population of donor PGCs was increased when the proliferation of PGCs of the recipient was compromised by $\mathrm{x}$ irradiation. It remains to be determined whether these donor cells are able to differentiate into functional gametes and to produce offspring.

Quail-chick chimeras with quail plumage were obtained in the present study, but these animals did not survive beyond 3 to 4 months of age. A small proportion of such chimeras also showed loss of quail plumage and its replacement with chicken plumage. The growth rate of these latter chimeras was reduced while they had quail plumage but increased after its substitution with chicken plumage (data not shown).

In conclusion, exposure of chicken embryos to soft $\mathrm{X}$-rays is a feasible approach to depletion of endogenous germ cells and consequent improvement in the efficiency of incorporation of donor PGCs. Further optimization of this approach may result in a greater extent of endogenous PGC depletion and donor cell incorporation in recipient embryos.

\section{Acknowledgments}

Part of this study was presented at the XXIII World Poultry Congress in Brisbane, Australia (2008), with travel support to Y.A. from the Japan Poultry Science Association. This study was supported in part by Grantsin-Aid for Scientific Research from the Japan Society for the Promotion of Science to T.O. 


\section{References}

Aoyama H, Asamoto K, Nojyo Y and Kinutani M. Monoclonal antibodies specific to quail embryo tissues: Their epitopes in the developing quail embryo and their application to identification of quail cells in quail-chick chimeras. Journal of Histochemistry and Cytochemistry, 40: 1769-1777. 1992.

Brinster RL and Avarbock MR. Germline transmission of donor haplotype following spermatogonial transplantation. Proceedings of the National Academy of Sciences of the United States of America, 91: 11303-11307. 1994.

Brinster RL and Zimmermann JW. Spermatogenesis following male germ-cell transplantation. Proceedings of the National Academy of Sciences of the United States of America, 91: 11298-11302. 1994.

Clouthier DE, Avarbock MR, Maika SD, Hammer RE and Brinster RL. Rat spermatogenesis in mouse testis. Nature, 381: 418-421. 1996.

Eyal-Giladi H and Kochav S. From cleavage to primitive streak formation: a complementary normal table and a new look at the first stages of the development of the chick. I. General morphology. Developmental Biology, 49: 321-337. 1976.

Gilbert SF. Developmental Biology. 8th ed. Sinauer Associates, Inc. Publishers. Sunderland, MA. 2006.

Hamburger V and Hamilton HL. A series of normal stages in the development of chick embryos. Journal of Morphology, 88: 49-92. 1951.

Kagami H. Developmental genetic analysis of the avian primordial germ cells and the applications for production of chimeric chickens. Journal of Poultry Science, 39: 131-139. 2002.

Kim MA, Park TS, Kim JN, Park HJ, Lee YM, Ono T, Lim JM and Han JY. Production of quail (Coturnix japonica) germline chimeras by transfer of gonadal primordial germ cells into recipient embryos. Theriogenology, 63: 774-782. 2005.

Li HC, Kagami H, Matsui K and Ono T. Restriction of proliferation of primordial germ cells by the irradiation of Japanese quail embryos with soft X-rays. Comparative Biochemistry and Physiology. Part A: Molecular and Integrative Physiology, 130: 133-140. 2001.

Lim JM, Kwon HM, Kim DK, Kim JN, Park TS, Ono T and Han JY. Selective decrease of chick embryonic primordial germ cells in vivo and in vitro by soft X-ray irradiation. Animal Reproduction Science, 95: 67-74. 2006.

Naito $M$ and Perry MM. Development in culture of the chick embryo from cleavage to hatch. British Poultry Science, 30: 251-256. 1989.

Naito M, Nirasawa K and Oishi T. Development in culture of the chick embryo from fertilized ovum to hatching. Journal of Experimental Zoology, 254: 322-326. 1990.

Naito M. Development of avian embryo manipulation techniques and their application to germ cell manipulation. Animal Science Journal, 74: 157-168. 2003a.
Naito M. Genetic manipulation in chickens. World's Poultry Science Journal, 59: 361-371. 2003b.

Nakamichi H, Sano A, Harumi T, Matsubara Y, Tajima A, Kosugiyama $\mathbf{M}$ and Naito $M$. Effects of soft X-ray irradiation to stage $\mathrm{X}$ blastoderm on restriction of proliferation of primordial germ cells in early chicken embryos. Journal of Poultry Science, 43: 394-400. 2006.

Nakamura Y, Yamamoto Y, Usui F, Mushika T, Ono T, Setioko AR, Takeda K, Nirasawa K, Kagami $\mathrm{H}$ and Tagami $\mathrm{T}$. Migration and proliferation of primordial germ cells in the early chicken embryo. Poultry Science, 86: 2182-2193. 2007.

Ogawa T, Aréchaga JM, Avarbock MR and Brinster RL. Transplantation of testis germinal cells into mouse seminiferous tubules. International Journal of Developmental Biology, 41: 111-122. 1997.

Ono T, Yokoi R, Maeda S, Nishida T and Aoyama H. Settlement of quail primordial germ cells in chicken gonads. Animal Science and Technology (Jpn.), 69: 546-555. 1998.

Perry MM. A complete culture system for the chick embryo. Nature, 331: 70-72. 1988.

Petitte JN, Clark ME, Liu G, Verrinder Gibbins AM and Etches RJ. Production of somatic and germline chimeras in the chicken by transfer of early blastodermal cells. Development, 108: 185-189. 1990.

Shinohara T, Kato M, Takehashi M, Lee J, Chuma S, Nakatsuji N, Kanatsu-Shinohara M and Hirabayashi M. Rats produced by interspecies spermatogonial transplantation in mice and in vitro microinsemination. Proceedings of the National Academy of Sciences of the United States of America, 103: 13624-13628. 2006.

Tajima A, Naito M, Yasuda Y and Kuwana T. Production of germ line chimera by transfer of primordial germ cells in the domestic chicken (Gallus domesticus). Theriogenology, 40: 509-519. 1993.

Tajima A, Hayashi H, Kamizumi A, Ogura J, Kuwana T and Chikamune T. Study on the concentration of circulating primordial germ cells (cPGCs) in early chick embryos. Journal of Experimental Zoology, 284: 759-764. 1999.

Tsunekawa N, Naito M, Sakai Y, Nishida T and Noce T. Isolation of chicken vasa homolog gene and tracing the origin of primordial germ cells. Development, 127: 27412750. 2000.

West A and Lähdetie J. X-irradiation-induced changes in the progression of type B spermatogonia and preleptotene spermatocytes. Molecular Reproduction and Development, 58: 78-87. 2001.

Yanai H. Statcel-The Useful Addin Forms on Excel. 2nd ed. OMS Publications, Tokorozawa, Japan. 2004.

Zhao DF, Yamashita H, Matsuzaki M, Takano T, Abe S, Naito $M$ and Kuwana T. Genetic factors affect the number of circulating primordial germ cells in early chick embryos. Journal of Poultry Science, 40: 101-113. 2003. 